\title{
Discordance in Colistin Susceptibility Test for Acinetobacter baumannii Showing Resistance: MicroScan versus Etest
}

\author{
Goeun Kang, Hyun \\ Soo Kim, Han-Sung \\ Kim, Wonkeun Song, \\ and Jae-Seok Kim \\ Department of Laboratory \\ Medicine, Hallym \\ University Kangdong Sacred \\ Heart Hospital, Hallym \\ University College of \\ Medicine, Seoul, Korea
}

\author{
Corresponding author: \\ Jae-Seok Kim \\ Department of Laboratory \\ Medicine, Hallym University \\ Kangdong Sacred Heart Hospital, \\ Hallym University College of \\ Medicine, 150 Seongan-ro, \\ Gangdong-gu, Seoul 05355, \\ Korea \\ Tel: +82-2-2224-2327 \\ Fax: +82-2-2224-2214 \\ E-mail: jaeseok@hallym.or.kr

\begin{abstract}
Background: Acinetobacter baumannii causes various hospital-acquired infections, its multidrug resistance is rapidly increasing worldwide. Although colistin is used in treatments against multidrug-resistant $A$. baumannii, resistance to colistin has also been reported recently. Few studies have reported colistin susceptibility testing using MicroScan. In this study, we compared colistin susceptibility tests for resistant $A$. baumannii by MicroScan (Siemens, USA) and Etest (BioMerieux, France).

Methods: We collected $115 \mathrm{~A}$. baumannii clinical isolates, showing colistin resistance (minimum inhibitory concentration $[\mathrm{MIC}] \geq 4 \mu \mathrm{g} / \mathrm{mL}$ ) by MicroScan, from July 2014 to March 2015 at Kangdong Sacred Heart Hospital. Species identification and antimicrobial susceptibility tests were performed using the MicroScan Neg Combo Panel Type 72. Additionally, Etest was also performed for comparison.

Results: Of the 115 isolates, Etest revealed that 103 (89.6\%) were colistin-susceptible $(\mathrm{MIC} \leq \mathrm{I} \mu \mathrm{g} / \mathrm{mL}$ ). Moreover, 52 isolates, showing a MIC of $4 \mu \mathrm{g} / \mathrm{mL}$ by MicroScan, were all susceptible to colistin. Only $12(19.0 \%)$ of 63 isolates, showing a MIC of $>4 \mu \mathrm{g} / \mathrm{mL}$ by MicroScan were resistant to colistin according to the Etest.

Conclusions: The MicroScan automated system, using the commercial broth microdilution method, exhibited some discrepancies with the Etest for colistin susceptibility in $A$. baumannii. Therefore, more practical and reliable susceptibility tests for colistin are required in clinical laboratories using MicroScan.
\end{abstract}

(J Lab Med Qual Assur 2015;37:209-213)

Key Words: Acinetobacter baumannii, Colistin, Microbial sensitivity tests, MicroScan, Etest

Received September 2, 2015, Revision received October 21, 2015, Accepted November 3, 2015
서론

Acinetobacter baumannii는 균혈증, 폐렴, 뇌수막염, 요로 감염 등의 병원감염을 일으키는 그람음성 막대균으로 전 세 계적으로 A. baumannii의 다제내성이 급격히 증가하고 있다 〔1,2]. Carbapenem 내성을 보이는 다제내성 A. baumannii 의 치료에 colistin (polymyxin E)을 사용할 수 있으나 최근 colistin에도 내성을 보이는 'pan-drug resistant' 균주도 발견 된다[1,3-5].

A. baumannii의 자동화 장비를 이용한 colistin 감수성 검사 와 Etest, 액체배지 미량희석법, 한천희석법과 비교한 연구들 이 있다[6-10]. Vitek2 (bioMerieux, Marcy l’Etoile, France) 는 colistin 감수성 검사의 신빙성에 대한 결과가 연구 간에 상 이하였고[6-8,10], colistin 내성 A. baumannii 18주를 포함 
한 최근 연구를 제외하고는[6] colistin 감수성 A. baumannii 만 포함되었거나 $[7,9,10]$ colistin 내성 A. baumannii는 내성 1 균주만 포함된 보고들로[8] 자동화 장비를 이용한 colistin 내성 A. baumannii의 항균제 감수성 검사에 대한 신빙성 을 판단하기 어렵다. MicroScan (MicroScan WalkAway 96 Plus system; Siemens Healthcare Diagnostics, West Sacramento, CA, USA)의 colistin 감수성 검사와 한천희석 법을 비교한 한 연구에서는 MicroScan에서 colistin 내성을 보 인 A. baumannii 4주에 있어 한천희석법에서 모두 감수성을 보여[7], 자동화 장비에서 colistin 내성을 보인 A. baumannii 의 항균제 감수성 검사결과에 대한 추가적인 평가가 필요하다.

액체배지 미량희석법과 한천희석법은 검사과정이 복잡하 여 많은 노력이 필요한 반면 Etest는 검사실에서 쉽게 시행 할 수 있는 장점이 있으나 신빙성에 대한 논란이 있다[6-12]. 이 연구에서는 MicroScan의 colistin 감수성 검사에 내성을 보인 A. baumannii를 대상으로 MicroScan 결과와 Etest (Etest Colistin CO256, bioMerieux)의 colistin 최소억제농도 (minimum inhibitory concentration, MIC)를 비교하였다.

\section{재료 및 방법}

\section{1. 대상}

2014년 7월부터 2015년 3월까지 미생물 배양검사가 의뢰 된 검체를 대상으로 하였다. A. baumannii는 278명 환자에서 1,028 주가 분리되었으며 이 중 MicroScan에서 colistin 내성 결과를 보이는 55 명 환자에서 분리된 A. baumannii 115 주를 대상으로 하였다. 균주는 객담 73 검체, 기관지세척액 13 검체, 농 12 검체, 혈액 5 검체, 소변 3 검체, 카테터 팁 3 검체, 피부조 직 3 검체, 담즙 1 검체, hemovac 1 검체, 흉수 1 검체에서 분리 되었다.

\section{MicroScan을 이용한 Colistin 감수성 검사}

MicroScan Neg Combo Panel Type 72 (Siemens Healthcare Diagnostics)를 사용하여 A. baumannii complex 동정과 항균제 감수성 검사를 시행하였다. A. baumannii의 colistin 내성은 Clinical and Laboratory Standards Institute (CLSI) 판정기준에 따라 $\mathrm{MIC}$ 값 $\geq 4 \mu \mathrm{g} / \mathrm{mL}$ 을 기준으로 하였다[13].

\section{Etest를 이용한 Colistin 감수성 검사}

MicroScan 장비에서 colistin 내성을 보인 A. baumannii 균주에 대하여 Etest (Colistin CO 256)를 실시하였다. 제조 사의 지침에 따라 $\mathrm{MIC}$ 를 측정하였으며 CLSI 판정기준에 따
라 $\mathrm{MIC} \leq 2 \mu \mathrm{g} / \mathrm{mL}$ 를 감수성, $\geq 4 \mu \mathrm{g} / \mathrm{mL}$ 을 내성으로 판정 하였고[13], MIC $3 \mu \mathrm{g} / \mathrm{mL}$ 는 내성으로 판정하였다. Colistin 내성의 정도관리를 위하여 Escherichia coli ATCC 25922와 Pseudomonas aeruginosa ATCC 27853을 동시에 검사하여 허용범위에 드는지 확인하였다.

\section{결과}

MicroScan에서 colistin 내성을 보인 115주 중 Etest에서 103 주(89.6\%)가 감수성을 보였으며 12 주(10.4\%)가 내성 결 과를 보였다. MicroScan MIC $4 \mu \mathrm{g} / \mathrm{mL}$ 인 52주는 Etest에서 MIC 0.094-0.38 $\mu \mathrm{g} / \mathrm{mL}$ 로 모두 감수성을 보였고, MicroScan $\mathrm{MIC}>4 \mu \mathrm{g} / \mathrm{mL}$ 인 63 주 중 51 주(81.0\%)는 Etest에서 $\mathrm{MIC}$ $0.094-2 \mu \mathrm{g} / \mathrm{mL}$ 로 감수성을 보였으며 12 주(19.0\%)는 Etest에 서 MIC 3-32 $\mu \mathrm{g} / \mathrm{mL}$ 로 내성 결과를 보였다(Table 1).

MicroScan과 Etest에서 모두 colistin 내성을 보인 A. baumannii 12 주는 colistin 치료를 받고 있는 5 명의 환자에서 중복 분리된 균주였다. 객담 5 검체, 기관지세척액 3 검체, 농 3

Table 1. Etest for 115 (all) isolates and 55 (first isolate only) Acinetobacter baumannii isolates showing colistin resistance by MicroScan

\begin{tabular}{|c|c|c|c|}
\hline \multicolumn{2}{|c|}{$\begin{array}{l}\text { Category (minimum inhibitory } \\
\text { concentration, } \mu \mathrm{g} / \mathrm{mL} \text { ) }\end{array}$} & \multirow{2}{*}{$\begin{array}{c}\text { No. of } \\
\text { isolates } \\
\text { (all isolates) }\end{array}$} & \multirow{2}{*}{$\begin{array}{c}\text { No. of isolates } \\
\text { (first isolates } \\
\text { only) }\end{array}$} \\
\hline MicroScan & Etest & & \\
\hline \multirow[t]{4}{*}{$\mathrm{R}(4)$} & $\mathrm{S}(0.094)$ & 7 & 7 \\
\hline & $S(0.125)$ & 43 & 29 \\
\hline & $\mathrm{S}(0.19)$ & 1 & 0 \\
\hline & $S(0.38)$ & 1 & 1 \\
\hline \multirow[t]{13}{*}{$\mathrm{R}(>4)$} & $S(0.094)$ & 6 & 2 \\
\hline & $S(0.125)$ & 33 & 10 \\
\hline & $\mathrm{S}(0.19)$ & 2 & 1 \\
\hline & $\mathrm{S}(0.25)$ & 2 & 1 \\
\hline & $S(0.38)$ & 7 & 1 \\
\hline & $S(2)$ & 1 & 1 \\
\hline & $\mathrm{R}(3)$ & 1 & 1 \\
\hline & $\mathrm{R}(4)$ & 2 & 1 \\
\hline & $\mathrm{R}(6)$ & 1 & 0 \\
\hline & $\mathrm{R}(8)$ & 2 & 0 \\
\hline & $\mathrm{R}(12)$ & 2 & 0 \\
\hline & $\mathrm{R}(24)$ & 3 & 0 \\
\hline & $\mathrm{R}(32)$ & 1 & 0 \\
\hline
\end{tabular}

Abbreviations: R, resistant; $\mathrm{S}$, sensitive. 
검체, 소변 1검체에서 분리되었으며 MicroScan MIC는 모두 $>4 \mu \mathrm{g} / \mathrm{mL}$ 였고 Etest MIC는 3-32 $\mu \mathrm{g} / \mathrm{mL}$ 였다.

한 환자에서 첫 번째 분리된 균주를 대상으로 하였을 때 MicroScan에서 colistin 내성을 보인 55주 중 53주(96.4\%)는 Etest에서 감수성이었으며 Etest에서도 내성을 보인 2균주의 Etest MIC는 각각 $3 \mu \mathrm{g} / \mathrm{mL}, 4 \mu \mathrm{g} / \mathrm{mL}$ 였다(Table 1).

\section{고찰}

Acinectobacter spp.는 국내 중환자실 환자에서 분리되는 병원감염의 주요 원인균으로서 다제내성균이 많다. 2011년 Korean Nationwide Surveillance of Antimicrobial Resistance 자료에 따르면 국내 20개 병원에서 수집한 Acinectobacter spp.의 내성률은 cefepime $66 \%$, imipinem $63 \%$, colistin $2 \%$ 를 보였다[14]. Colistin은 lipopolysaccharide의 lipid A와 작 용하여 외막을 무력화함으로써 그람음성균에 효과적이지만 신독성과 신경독성의 부작용 때문에 흔히 사용되지 않았으나 다제내성 그람음성균에 의한 감염이 늘어남에 따라 그 사용이 다시 증가되었다[1,15].

A. baumannii의 colistin 내성 보고가 증가하고 있어 $[1,3,4]$ 신빙성 있는 감수성검사가 요구된다. CLSI에서는 액체배지 미량희석법이나 한천희석법을 colistin 감수성시험의 표준방 법으로 제시하나 colistin 감수성에 대한 자동화 장비의 신빙 도를 평가한 연구는 많지 않다. MicroScan의 colistin 내성 A. baumannii에 대한 연구는 많지 않으나 한 연구에서는 94균주 중 MicroScan에서 colistin 내성 결과를 보인 4개의 균주가 한 천희석법에서 모두 감수성을 보인 결과가 있다[7].

Etest는 colistin 감수성 A. baumannii에서 액체배지 미량 희석법이나 한천희석법과 높은 일치도를 보여[7-11] 신빙성 있는 검사로 여겨졌으나 colistin 내성 균주에서 9-25\%의 very major error를 보인다[6,11]. Etest와 액체배지 미량희석법을 비교한 연구에서 115 개의 A. baumannii 임상 균주 중 액체배 지 미량희석법에서 감수성을 보인 93균주에 있어 Etest와 결 과가 모두 일치하였으나 colistin 내성인 22균주에 있어 Etest 에서는 2균주가 감수성으로 나타나는 very major error가 있 었다[11]. Vitek2와 Etest를 비교한 연구에서 carbapenem 내 성 A. baumannii 20 주의 colistin 감수성 검사결과 액체배지 미량희석법에 비해 Etest에서 낮은 MIC를 보였으며 액체배지 미량희석법에서 내성인 5 주(25\%)가 Etest에서 감수성 결과를 보이는 very major error가 있었다. 반면 액체배지 미량희석 법에서 감수성이나 Vitek2에서 내성을 보인 major error 2주 $(10 \%)$ 가 있었다[6].
Vitek2와 Etest를 비교한 다른 연구에서 1주의 colistin 내 성 A. baumannii와 6주의 colistin 감수성 A. baumannii를 포함한 그람음성균 80주의 colistin 감수성 검사에서 Vitek2와 Etest는 액체배지 미량희석법의 MIC와 $\log _{2}$ 희석 배수 차이 가 \pm 2 이내인 균주가 각각 $100 \%, 94.7 \%$ 로 액체배지 미량희 석법과 높은 일치를 보였다[8]. Acinetobacter spp. 58주를 포 함한 그람음성간균 172 주를 대상으로 Vitek2와 Etest를 비교 한 연구에서는 colistin 내성인 그람음성간균이 Vitek2에서는 감수성을 보인 very major가 $18 \%$ 에서 나타났으나 이 연구에 포함된 Acinetobacter spp.는 모두 colistin 감수성인 균주였 으며 Acinetobacter spp.에 국한하면 Vitek2는 한천희석법과 $100 \%$ 일치를, Etest는 $99 \%$ 의 일치를 보였다[10].

Phoenix system (Becton Dickinson, Sparks, MD, USA) 과 Etest를 비교한 연구에서는 A. baumannii 100주가 모두 colistin에 감수성으로 나타나 $100 \%$ 일치하는 결과를 보였으 나 colistin 내성 균주가 포함되지 않아 내성 균주에 대한 검사 의 유용성을 평가하기 어려운 한계가 있다[9].

혈액검체에서 분리된 Acinetobacter spp.를 대상으로 Vitek2, MicroScan, Etest, 한천희석법을 비교한 연구에서 Vitek2와 Etest는 한천희석법과 99\% 이상의 categorical agreement 를 보였으나 MicroScan은 한천희석법과 87.3\%의 categorical agreement를 보였다. Vitek2와 달리 MicroScan에서 결과 차 이가 발생하는 원인은 MIC 값을 다양하게 검사하는 Vitek2 $(\leq 0.5-\geq 16 \mu \mathrm{g} / \mathrm{mL})$, Etest $(0.016-256 \mu \mathrm{g} / \mathrm{mL})$ 와는 달리 MicroScan은 $\leq 2,4,>4 \mu \mathrm{g} / \mathrm{mL}$ 로 2 개의 well로만 검사하는 것에 따른 한계일 수 있다[7].

이 연구는 9 개월간 분리된 A. baumannii 1,028주 중 액체 배지 미량희석법을 사용하는 자동화 장비인 MicroScan에서 colistin MIC $4 \mu \mathrm{g} / \mathrm{mL}$ 이상으로 내성 결과를 보이는 115 주 를 대상으로 Etest를 시행하였다. 115주 중 103주(89.6\%)가 Etest MIC 0.094- $2 \mu \mathrm{g} / \mathrm{mL}$ 로 감수성을 보여 MicroScan의 결 과와 불일치하였다. Colistin은 양쪽 친매성 물질로 폴리스틸 렌 등의 검사용기와 결합하여 검사 시 농도가 낮게 변할 수 있 으며 배지에서 확산이 잘 되지 않는다[13,16,17]. 불일치의 원 인으로는 MicroScan의 well 표면과 colistin 결합으로 인해 colistin 농도가 낮아지는 등의 원인으로 발생한 오류일 가능성 과 MicroScan이 2개의 well로만 검사하는 것에 따른 한계로 인한 오류일 가능성, Etest에서 colisitn의 낮은 확산능으로 인 해 오류를 보였을 가능성이 있다.

Etest나 자동화장비를 이용한 A. baumannii의 colistin 감 수성 검사는 빠르고 간편한 장점이 있으나 colistin에 내성 을 보인 균주에 대한 더 많은 연구가 필요할 것으로 보인다. 
MicroScan을 사용하는 검사실에서는 colistin 내성을 보인 A. baumannii에서 Etest 결과와의 일치도가 높지 않았으므로 액 체배지 미량희석법, 한천희석법과 같은 추가적인 감수성 검사 를 고려해야 할 것으로 생각한다.

\section{REFERENCES}

1. Cai Y, Chai D, Wang R, Liang B, Bai N. Colistin resistance of Acinetobacter baumannii: clinical reports, mechanisms and antimicrobial strategies. J Antimicrob Chemother 2012;67:1607-15.

2. Koh EM, Lee SG, Kim CK, Kim M, Yong D, Lee K, et al. Microorganisms isolated from blood cultures and their antimicrobial susceptibility patterns at a university hospital during 1994-2003. Korean J Lab Med 2007;27:26575.

3. Ko KS, Suh JY, Kwon KT, Jung SI, Park KH, Kang CI, et al. High rates of resistance to colistin and polymyxin $B$ in subgroups of Acinetobacter baumannii isolates from Korea. J Antimicrob Chemother 2007;60:1163-7.

4. Park YK, Peck KR, Cheong HS, Chung DR, Song JH, Ko KS. Extreme drug resistance in Acinetobacter baumannii infections in intensive care units, South Korea. Emerg Infect Dis 2009;15:1325-7.

5. Manchanda V, Sanchaita S, Singh N. Multidrug resistant acinetobacter. J Glob Infect Dis 2010;2:291-304.

6. Dafopoulou K, Zarkotou O, Dimitroulia E, Hadjichristodoulou C, Gennimata V, Pournaras S, et al. Comparative Evaluation of Colistin Susceptibility Testing Methods among Carbapenem-Nonsusceptible Klebsiella pneumoniae and Acinetobacter baumannii Clinical Isolates. Antimicrob Agents Chemother 2015;59:4625-30.

7. Lee SY, Shin JH, Lee K, Joo MY, Park KH, Shin MG, et al. Comparison of the Vitek 2, MicroScan, and Etest methods with the agar dilution method in assessing colistin susceptibility of bloodstream isolates of Acinetobacter species from a Korean university hospital. J Clin Microbiol 2013;51:1924-6.
8. Lo-Ten-Foe JR, de Smet AM, Diederen BM, Kluytmans JA, van Keulen PH. Comparative evaluation of the VITEK 2, disk diffusion, etest, broth microdilution, and agar dilution susceptibility testing methods for colistin in clinical isolates, including heteroresistant Enterobacter cloacae and Acinetobacter baumannii strains. Antimicrob Agents Chemother 2007;51:3726-30.

9. Sinirtaş M, Akalin H, Gedikoglu S. Investigation of colistin sensitivity via three different methods in Acinetobacter baumannii isolates with multiple antibiotic resistance. Int J Infect Dis 2009;13:e217-20.

10. Tan TY, Ng SY. Comparison of Etest, Vitek and agar dilution for susceptibility testing of colistin. Clin Microbiol Infect 2007;13:541-4.

11. Arroyo LA, Garcia-Curiel A, Pachon-Ibanez ME, Llanos AC, Ruiz M, Pachon J, et al. Reliability of the E-test method for detection of colistin resistance in clinical isolates of Acinetobacter baumannii. J Clin Microbiol 2005;43:903-5.

12. Behera B, Mathur P, Das A, Kapil A, Gupta B, Bhoi S, et al. Evaluation of susceptibility testing methods for polymyxin. Int J Infect Dis 2010;14:e596-601.

13. Clinical and Laboratory Standards Institute. Performance standards for antimicrobial susceptibility testing. 25th informational supplement, M100-S25. Wayne (PA): Clinical and Laboratory Standards Institute, 2015.

14. Lee Y, Kim YA, Song W, Lee H, Lee HS, Jang SJ, et al. Recent trends in antimicrobial resistance in intensive care units in Korea. Korean J Nosocomial Infect Control 2014;19:29-36.

15. Nation RL, Li J. Colistin in the 21st century. Curr Opin Infect Dis 2009;22:535-43.

16. Albur M, Noel A, Bowker K, Macgowan A. Colistin susceptibility testing: time for a review. J Antimicrob Chemother 2014;69:1432-4.

17. Humphries RM. Susceptibility testing of the polymyxins: where are we now? Pharmacotherapy 2015;35:22-7. 


\section{MicroScan에서 Colistin 내성을 보인 Acinetobacter} baumannii 균주의 Etest Colistin 결과와의 불일치 강고은 • 김현수 • 김한성 • 송원근 • 김재석

한림대학교 의과대학 한림대학교강동성심병원 진단검사의학교실

배경: Acinetobacter baumannii는 다양한 병원감염을 일으키며, 전 세계적으로 A. baumannii 의 다제내성이 급격히 증가하고 있다. 다제내성 A. baumannii의 치료에 colisti이 사용되나 최근 colistin에도 내성을 보이는 균주도 보고되고 있다. MicroScan (Siemens, USA)의 colistin 감수 성 검사에 대한 연구는 많지 않다. 이 연구에서는 MicroScan의 colistin 감수성 검사에 내성인 $A$. baumannii를 대상으로 MicroScan 결과와 Etest (bioMerieux SA, France) 결과를 비교하였다.

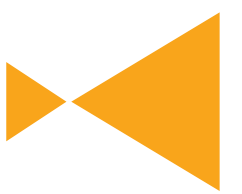

Journal of

LABORATORY MEDICINE and

QUALITY ASSURANCE 방법: 2014년 7월부터 2015년 3월까지 미생물 배양검사가 의뢰된 MicroScan에서 colistin 내성 결 과(minimum inhibitory concentration [MIC] $\geq 4 \mu \mathrm{g} / \mathrm{mL}$ )를 보이는 A. baumannii 115주를 대상 으로 하였다. 균동정과 감수성 검사는 MicroScan Neg Combo Panel Type 72를 사용하여 시행하 였다. Etest를 이용한 colistin 감수성 검사를 실시하고 비교하였다.

결과: MicroScan 장비에서 colistin 내성 결과를 보인 115주 중 Etest에서 103주(89.6\%)가 MIC $\leq 2$ $\mu \mathrm{g} / \mathrm{mL}$ 로 감수성을 보였다. MicroScan에서 MIC $4 \mu \mathrm{g} / \mathrm{mL}$ 인 52주는 Etest에서 모두 감수성을 보였 고, MicroScan에서 MIC >4 $\mu \mathrm{g} / \mathrm{mL}$ 인 63주 중 12주(19.0\%)만 Etest에서도 내성 결과를 보였다.

결론: 액체배지 미량희석법을 응용한 자동화장비인 MicroScan은 A. baumannii의 colistin 감수성 검사에서 Etest와 일치도가 높지 않았다. MicroScan을 사용하는 검사실에서는 실용적이고 신뢰성 있는 colistin 감수성 검사가 필요할 것으로 생각한다.

(J Lab Med Qual Assur 2015;37:209-213)

\section{교신저자: 김재석}

